NBER WORKING PAPER SERIES

TRADE WARFARE: TARIFFS AND CARTELS

James A. Brander

Barbara J. Spencer

Working Paper No. 1193

NATIONAL BUREAU OF ECONOMIC RESEARCH 1050 Massachusetts Avenue

Cambridge, MA 02138

August 1983

The research reported here is part of the NBER's research program in International Studies and program in Productivity (World

Economy). Any opinions expressed are those of the authors and not those of the National Bureau of Economic Research. 


\title{
Trade Warfare: Tariffs and Cartels
}

\begin{abstract}
National governments have incentives to intervene in international markets, particularly in encouraging export cartels and in imposing tariffs on imports from imperfectly competitive foreign firms. Although the optimal response to foreign monopoly is usually a tariff, a specific subsidy will be optimal if demand is very convex, as with constant elasticity demand. If ad valorem tariffs or subsidies are considered, a subsidy is optimal if the elasticity of demand increases as consumption increases. The critical conditions in both ad valorem and specific cases hold generally for Cournot ologopoly. Noncooperative international policy equilibrium will be characterized by export cartels and rent-extracting tariffs.
\end{abstract}

\author{
James A. Brander \\ Department of Economics \\ University of British \\ Columbia \\ Vancouver, British Columbia \\ V6T 1 Y2 CANADA
}

Barbara J. Spencer Department of Economics Boston College Chestnut Hi11, MA 02167 $617 \quad 552-3694$ 


\section{Trade Warfare: Tariffs and Cartels}

James A. Brander/Queen's University

Barbara J. Spencer/Boston College

1. Introduction

In recent years considerable attention has been focused on the use of export cartels to extract rents from international markets. Indeed, the formation of the OPEC oil cartel is probably the single economic event of greatest notoriety to have occurred in the past dozen years. In addition, national governments, particularly in developed countries, have engaged in a variety of policies designed to enhance the market power of domestically based export industries, including encouragement of "cooperation" between domestic firms, and provision of protected home markets. ${ }^{1}$ The general point is that the international marketplace provides strong incentives for unilateral policies aimed at promoting the interests of domestic firms, leading to intervention in industries which might otherwise be quite competitive.

Relatively little attention has been paid to the optimal response by consuming nations to foreign imperfect competition, and in particular, to foreign cartelization. ${ }^{2}$ In this paper our first objective is to examine the optimal tariff response. If foreign firms earn rents from sales in the domestic country, some of these rents can be extracted by using a tariff. ${ }^{3}$ Imports will fall and so will consumer welfare but this can usually be more than offset by increased tariff revenue. Surprisingly, however, the efficient response to foreign cartelization is, in some cases, to subsidize imports. 
The conditions underlying whether a tariff or a subsidy is optimal vary depending on whether it is ad valorem or specific tariffs that are under consideration. With a specific tariff or subsidy, whether a subsidy is optimal depends on the convexity of demand. In the ad valorem case, the critical condition concerns whether the elasticity of demand rises or falls along the demand curve. In both cases the condition for choosing between a tariff or subsidy applies to foreign monopoly and, more generally, to any foreign noncooperative Cournot oligopoly, regardless of the number of firms in the industry.

A second objective of the paper is to draw attention to the incentive structure of international trade negotiations. A noncooperative equilibrium arising from independent pursuit of national objectives will be characterized by inefficiently high levels of policy intervention. Multilateral negotiations such as those carried out under GATT can be viewed as attempts to move toward the (collectively superior) joint maximizing solution. However, in the absence of any clearly specified enforcement mechanism that would make the liberalized joint-maximizing solution individually rational, the results of such negotiations have to be regarded as fragile outcomes that are likely to require constant attention if they are to be maintained.

Section 2 of the paper sets out the basic framework and characterizes the optimum specific tariff in the presence of foreign imperfect competition. Section 3 examines the optimum tariff for the particular cases of foreign monopoly and perfect competition. The optimal ad valorem tariff is considered in section 4 . Section 5 offers an interpretation of our results using "terms of trade" arguments associated with the standard monopoly tariff problem Section 6 considers the optimal tariff for $n$-firm 
Cournot oligopoly, and section 7 examines the interaction between the degree of foreign imperfect competition and the optimum tariff Section 8 contains concluding remarks.

2. The Optimum Specific Tariff for Extracting Rent from Foreign Firms

Taking the view that the industry in question is small compared to the entire economy so that partial equilibrium analysis is appropriate, we assume that domestic demand arises from a utility function that can be approximated by the form

$$
\mathrm{U}=\mathrm{u}(\mathrm{X})+\mathrm{m}
$$

where $\mathrm{X}$ is consumption of the good under consideration and $\mathrm{m}$ is expenditure on other goods. Use of this approximation for both positive and normative analysis assumes away a number of theoretical difficulties, including income effects, aggregation problems, and second-best problems induced by other distortions in the economy. These problems are complicated but reasonably well understood and trying to deal with them here would obscure the basic focus of the paper, which is the existence of a pure rent-seeking incentive for tariffs.

Inverse demand is just the derivative of $u$ :

$$
\mathrm{p}=\mathrm{u}^{\prime}(\mathrm{X}) ; \mathrm{p}^{\prime}<0
$$

where $\mathrm{p}$ represents price. Consumer surplus $\mathrm{u}(\mathrm{X})$ - $\mathrm{pX}$ is, in this case, a consistent measure of the benefit to domestic consumers from consuming good $X$. Therefore, with specific tariff $t$, the net domestic gain, $G$, from imports of good $\mathrm{X}$ is

$$
G(t)=u(X)-p X+t X
$$


The net benefit consists of two parts; consumer surplus and tariff revenue. One dollar of tariff revenue counts the same as one dollar of consumer surplus. The sales level $\mathrm{X}$ will depend on the tariff, and the optimal specific tariff is found by setting $G_{t}=d G / d t=0$ Using subscripts to denote derivatives we have

$$
G_{t}=-X\left(P_{t}-1-t X_{t} / X\right)=0
$$

where $\mathrm{P}_{t} \equiv \mathrm{P}^{\prime} \mathrm{X}_{t}$. Letting $\mu \equiv-t \mathrm{X}_{t} / \mathrm{X}$, the elasticity of imports with respect to the tariff, we can rewrite expression (4) as

$$
1-\mathrm{P}_{\mathrm{t}}=\mu
$$

Condition (5) characterizes the optimum tariff rule for extracting rent from foreign firms, provided second order condition $G_{t t}<0$ is satisfied.

The elasticity of imports with respect to the tariff and $\mathrm{p}_{t}$, the effect of the tariff on consumer price, must sum to one. The term $p_{t}$ reflects the decline in consumer surplus as the tariff is increased. If the country's objective were simply to maximize tariff revenue without considering the loss of consumer surplus the solution would require $\mu=1$. In our setting $\mu$ must be less than one at the solution since $p_{t}$ is generally positive.

A useful rearrangement of (4) is

$$
t *=x\left(p_{t}-1\right) / x_{t}
$$

where $t *$ is the optimum tariff. Furthermore, denoting the producer 
price, $p^{-t}$, by $q$, and observing that $q_{t}=p_{t}-1,(6)$ can be rewritten as $t *=x_{t} / x_{t}$

$x_{t}$ is negative. From (6), a positive $t *$ is obtained if

$P_{t}<1$. Equivalently, from $\left(6^{\prime}\right), t^{*}>0$ if the effect of increasing the tariff is to reduce the producer price. If, on the other hand, $q_{t}>0$, the optimal tariff is negative: imports should be subsidized, for, in this case, consumer price falls by more than the subsidy. In the next section we show, perhaps surprisingly, that subsidization arises for some relatively standard demand and cost structures.

3. The Specific Tariff: Monopoly and Perfect Competition

We first consider the case of a foreign monopoly cartel. Presumably the cartel supplies several markets of which the domestic country is only one. It is assumed that the monopoly cartel is able to discriminate among markets and maximize profit in each country separately. (Any constraints imposed by arbitrage possibilities are not binding over the relevant range.) Choices in different markets might be connected through the dependence of marginal cost on total output. This complication can be eliminated by assuming that marginal cost is constant in the range of output under consideration.

An alternative setting is that the foreign monopolist sells only in the domestic market, in which case nonconstant marginal cost can be handled very easily. In the case of a specific tariff, the variable profit in the domestic market for the monopolist is

$$
\pi(X)=X p(X)-c(X)-t X
$$


Letting $c^{\prime}$ denote marginal cost, the first order condition is

$$
\pi_{x}=p+p^{\prime} x-c^{\prime}-t=0
$$

with second order condition

$$
\begin{aligned}
\pi_{\mathrm{XX}} & =2 \mathrm{p}^{\prime}+\mathrm{X} \mathrm{p}^{\prime \prime}-\mathrm{c}^{\prime \prime} \\
& =\mathrm{p}^{\prime}(2+\mathrm{R})-\mathrm{c}^{\prime}<0
\end{aligned}
$$

where $\mathrm{R} \equiv \mathrm{Xp}^{\prime}{ }^{\prime} / \mathrm{p}^{\prime}$.

The variable $R$ is a measure of the relative curvature of the demand curve. It can also be interpreted as the elasticity of $\mathrm{P}^{\prime}$. A restriction on the value of $\mathrm{R}$ provides an important regularity condition when dealing with general demand curves, particularly in the case of imperfect competition. ${ }^{4}$ The inverse demand curve $\mathrm{p}(\mathrm{X})$ is concave to the origin, linear or convex as $R$ is positive, zero, or negative, respectively. Larger absolute values of $R$ are associated with greater relative curvature

In order to obtain $\mathrm{p}_{t}\left(\equiv \mathrm{p}^{\prime} \mathrm{x}_{\mathrm{t}}\right)$, we first obtain $\mathrm{x}_{t}$, the effect of a tariff (or subsidy) on the supply of imports, by totally differentiating (8) with respect to $X$ and $t$.

$$
\mathrm{x}_{\mathrm{t}}=1 / \pi_{\mathrm{XX}}=1 /\left[\mathrm{p}^{\prime}(2+\mathrm{R})-\mathrm{c}^{\prime \prime}\right]<0
$$

$\mathrm{X}_{\mathrm{t}}$ is negative by the second order condition: an increase in the tariff reduces the quantity of $\mathrm{X}$ sold by the foreign monopoly in the domestic country. From (11),

$$
\left.p_{t}=1 /(2+R)-c^{\prime \prime} / p^{\prime}\right]
$$


Also, using (11) and (12) we can write (6) as $t^{*}=-p^{\prime} x\left(1+R-c^{\prime} / p^{\prime}\right)$. If marginal cost is constant, then $p_{t}$ is less than, equals, or exceeds 1 , and the optimal tariff is positive, zero, or negative according to whether $R>-1, R=-1$ or $R<-1$ respectively

If $R>-1$, so that demand is not "too" convex to the origin and if marginal cost is constant or increasing, then from (12), $\mathrm{p}_{t}<1$ and the optimum tariff $t^{*}$ is positive. Since $R=X p^{\prime \prime} / p^{\prime}$, all concave or linear demand curves satisfy $R \geq 0$ and therefore $R>-1$. (The. Iinear case, for which $R=0$, was considered by Katrak (1977) and Svedberg (1979).)

The possibility that imports from the foreign monopolist should be subsidized arises if $p_{t}>1$. From expression (12), $p_{t}$ may exceed 1 for two reasons. The first possibility is that marginal cost is decreasing sufficiently fast that $c^{\prime \prime} / p^{\prime}>(1+R)\left(\right.$ but $\left.c^{\prime \prime} / p^{\prime}<(2+R)\right)$ to satisfy the firm's second order condition). The second possibility is that demand is sufficiently convex. In particular if $\mathrm{c}^{\prime \prime}=0$, then $\mathrm{R}$ must be less than -1 for subsidization to be welfare-maximizing.

This latter possibility is illustrated by a demand curve with constant elasticity in the relevant range. Differentiating inverse demand $\mathrm{p}=a \mathrm{X}^{-1 / \eta}$ with respect to $\mathrm{X}$ where $\mathrm{n}$ is the (positive) constant elasticity we obtain $R=-1-(1 / \eta)$. $\eta$ must exceed 1 to satisfy the first order condition for a monopolist, so $R$ must be between -2 and -1 , which is consistent with the monopolist's second order condition (9) if $c^{\prime \prime}$ is not too negative. From (12) $c^{\prime \prime} \geq 0$ is sufficient to ensure that $p_{t}$ exceeds 1 and (6) implies that a subsidy is called for.

This can be understood by noting that $R<-1$ is equivalent to demand being steeper than marginal revenue. The slope of demand is 
$\mathrm{P}^{\prime}$ and the slope of marginal revenue $(\mathrm{mr})$ is $\mathrm{X}_{\mathrm{p}^{\prime}}^{\prime}+2 \mathrm{p}^{\prime}$. Then $\mathrm{mr} \mathrm{r}^{\prime}-\mathrm{p}^{\prime}=$ $X p^{\prime \prime}+p^{\prime}=P^{\prime}(R+1)$. Thus $R<-1$ if and only if $m r^{\prime}-P^{\prime}$ is positive. With constant marginal cost, a subsidy, $s$, then causes price to fall by more than the subsidy. This is illustrated in Figure 1 . As a subsidy $s$ is introduced price charged moves from $\mathrm{P}_{0}$ to $\mathrm{P}_{1}$ and quantity from $x_{0}$ to $x_{1}$. The cost of the subsidy is shown by the vertically shaded region which, as drawn, clearly has less area than the diagonally shaded region, which represents the gain in consumers' surplus.

\section{- Figure 1 -}

The subsidy increases the welfare of both the domestic country and the foreign firm and cannot therefore be regarded as a "rentextracting" policy. This curious result arises because the subsidy causes price to fall sufficiently that the additional consumer surplus more than compensates for the cost of the subsidy.

Suppose now that the foreign industry is perfectly competitive. If the long run industry supply curve is horizontal (although individual firms may have U-shaped average cost curves), then $P_{t}=1$ : a tariff causes an equal increase in the domestic price. In this case expression (6) implies that $t^{*}=0$ and the optimum policy is free trade.

If a foreign perfectly competitive industry has an upward sloping supply curve of exports to the domestic country, then $\mathrm{p}_{t}<1$ and, by expression (6), the country gains by using a tariff. Hence, 
in the special case of perfect competition, our tariff rule is essentially a partial equilibrium version of the "monopoly tariff" or "terms of trade" argument for using a tariff. Figure 2 illustrates the extraction of rent from a competitive foreign industry with upward sloping supply. The curve denoted ME (for marginal expenditure) is marginal to supply curve $S$ and the optimum occurs where ME equals marginal benefit (price) with tariff $t *$ as shown.

4. The Optimum ad Valorem Tariff

Consider now an ad valorem tariff or subsidy. It is still the case that either a tariff or subsidy may be optimal, depending on demand and cost. Interestingly, however, the conditions on demand that lead to a subsidy are rather different than in the case of a specific tariff or subsidy: an ad valorem tariff affects the first order condition of the foreign monopolist in a structurally different way than does a specific tariff and therefore, for given demand and cost conditions, gives rise to different price effects.

We denote the ad valorem tariff by $v$, so the relationship between consumer price $\mathrm{p}$ and producer price $\mathrm{q}$ is given by

$$
p(v)=q(v)(1+v)
$$

Tariff revenue is $q v x$, and we use $\tau(v)$ to represent the tariff per unit of imports associated with ad valorem tariff $v$. Therefore $\tau=v q$ 
and total tariff revenue can be written $\tau X$. Net domestic benefit $G$, is consumer benefit plus tariff revenue.

$$
G(v)=u(X(v))-p X+\tau X
$$

Expression (14) is equivalent to expression (5), except that here it is the ad valorem $v$, rather than the specific tariff $t$ that is the choice variable. The first order condition associated with a maximum of $G$ is then

$$
\mathrm{G}_{\mathrm{v}}=-\mathrm{X}\left(\mathrm{P}_{\mathrm{v}}-\tau_{\mathrm{v}}-\tau \mathrm{X}_{\mathrm{v}} / \mathrm{X}\right)=0
$$

which corresponds to (4) for the specific tariff. Rearranging (15) to solve for the optimum level of $\tau$ yields

$$
\tau^{*}=\mathrm{X}\left(\mathrm{P}_{\mathrm{v}}-\tau_{\mathrm{v}}\right) / \mathrm{X}_{\mathrm{v}}
$$

Since $p=q(1+v)$ and $\tau=v q$ it follows that $p=q+\tau$ and therefore that $\mathrm{q}_{\mathrm{v}}=\mathrm{p}_{\mathrm{v}}-\tau_{\mathrm{v}}$, which is substituted in (16) to obtain

$$
\tau * \mathrm{Xq}_{\mathrm{v}} / \mathrm{X}_{\mathrm{v}}
$$

As with the specific tariff case, it is the sign of the comparative static effect of the tariff on producer price that determines whether a tariff or subsidy is optimal. $X_{v}$ is negative (as is easily shown), consequently expression (16') implies that the optimum tariff per unit of imports and corresponding ad valorem tariff itself are positive if $q_{v}$ is negative. A subsidy is optimal if $\mathrm{q}_{\mathrm{v}}$, the effect of the ad valorem tariff on producer price, is positive.

Because an ad valorem tariff affects a foreign cartel's behaviour differently than does a specific tariff, the conditions for $q_{v}<0$ differ from the conditions for $q_{t}<0$. To determine the sign of $q_{v}$ consider the profit-maximizing problem of the foreign cartel:

$$
\max \pi=\mathrm{pX} /(I+\mathrm{v})-\mathrm{c}(\mathrm{X})
$$


From the first order condition $\pi_{X}=0$ we obtain

$$
\mathrm{q}(\mathrm{v}) \equiv \mathrm{p}(\mathrm{v}) /(1+\mathrm{v})=n \mathrm{c}^{\prime}(\mathrm{x}) /(n-1)
$$

where $\eta$ is the (positive) elasticity of demand: $\eta=-p / X P^{\prime}(X)$. Also, using the second order condition $\pi_{x x}<0$, it can be seen that $\mathrm{dX} / \mathrm{dv} \equiv \mathrm{X}_{\mathrm{v}}<0$. Then, if marginal cost is constant, taking the derivative of (18) yields

$$
\mathrm{dq} / \mathrm{dv} \equiv \mathrm{q}_{\mathrm{v}}=-\mathrm{c}^{\prime}(\mathrm{x}) \eta_{\mathrm{x}} \mathrm{x}_{\mathrm{v}} /(n-1)^{2}
$$

where $\eta_{X}=d n / d x$. Since $x_{v}<0$ and $c^{\prime}(x)>0$ it follows that the sign of $q_{v}$ depends on whether $\eta$ rises or falls along the demand curve. 6

$$
\begin{array}{llll}
\mathrm{q}_{\mathrm{v}}>0 & \text { if } \eta_{\mathrm{X}}>0 & \text { ( subsidy) } \\
\mathrm{q}_{\mathrm{v}}=0 & \text { if } \eta_{\mathrm{X}}=0 & \text { (constant elasticity } \Rightarrow \text { non-intervention) (19b) } \\
\mathrm{q}_{\mathrm{v}}<0 & \text { if } \eta_{\mathrm{X}}<0 & \text { (tariff) }
\end{array}
$$

The ad valorem regime is less likely than the specific regime to give rise to a welfare-improving subsidy. With constant marginal cost, constant elasticity demand implies an optimal subsidy for the specific regime but implies the optimality of non-intervention in the ad valorem case. It can be shown that the condition $R<-1$, which is sufficient for a subsidy in the specific case, is necessary but not sufficient for a subsidy in the ad valorem case. If marginal cost is increasing rather than constant the subsidy of course becomes less likely in both regimes

5. Tariffs and the Terms of Trade

The relationship between our approach with imperfect competition and the standard monopoly tariff analysis should be clarified. (The monopoly tariff argument is associated with Johnson (1953), among others.) The monopoly (or optimum) tariff is used when the 
foreign industry is perfectly competitive and the domestic country is large enough to have influence on world prices. In this paper foreign firms or cartels are imperfectly competitive and may price discriminate among markets. (OPEC is not the best example of price discrimination although even here most major producers charge different prices at home than they do in "world" markets.) With price discrimination even a country that is far too small to affect world prices can influence the profit-maximizing output and price chosen by foreign producers for the domestic market. From a purely domestic point of view industry specific tariffs are then attractive tools to extract rent.

Even without price discrimination imperfectly competitive firms change the analysis. Just as a monopoly has no supply curve, the foreign country has no offer curve. Imagine that the industry described here is embedded in a simple general equilibrium model. There is one other good, denoted $\mathrm{m}$, which is produced competitively and whose price is normalized to equal 1. Domestic preferences are still represented by expression (1), and the domestic country produces only good $\mathrm{m}$. Imports of good $\mathrm{X}$ are paid for with exports of good $\mathrm{m}$ so as to maintain balanced trade.

In the pre-tariff state, the domestic country consumes at $A$ and produces at $B$ in Figure 3 . The balanced trade line joining $B$ and $A$ has slope -p. Note, however, that this terms of trade line is not a comsumption possibility frontier. Because the foreign cartel chooses both price and quantity given perceived demand, the consumption possibilities set (with trade) is a single point. A tariff or subsidy 
shifts the position of this point and makes consumer price differ from the slope of the balanced trade line.

The effect of a welfare-improving tariff is to shift out the equilibrium bálanced trade line as illustrated in Figure 3, leading to consumption at point $A^{\prime}$ and higher domestic welfare

\section{- Figure 3 -}

In either the ad valorem or specific regimes, if a tariff is optimal the consumer price rises by less than the tariff revenue per unit of imports (see (6) and (16)), so that the producer price must fall, improving the country's terms of trade. The subsidy case is rather interesting. For a subsidy to be optimal we require that the subsidy must cause the consumer price to fall by more than the subsidy, improving the country's terms of trade net of the subsidy, ${ }^{8}$ With an optimal subsidy, the postsubsidy producer relative price is less than the pre-subsidy price. Once again the equilibrium balanced trade line shifts out. Indeed, deciding whether a tariff or subsidy would be better amounts to finding which would shift out the equilibrium balanced trade line. ${ }^{9}$

In the tariff case, the foreign country loses more than the domestic country gains. In the subsidy case, both gain. Without any changes in production, the impact effect of the subsidy is to improve the foreign country's terms of trade. Profit maximizing behaviour by the foreign cartel then leads it to increase production and to reduce the producer price by more than the subsidy, which worsens the foreign terms of trade compared to the pre-subsidy state. Despite the worsened terms of trade the foreign country gains through a production effect as 
world consumption of $\mathrm{X}$ rises toward the efficient level.

6. Extracting Rent from a Cournot Oligopoly

Pure monopoly and perfect competition are of some interest but are not, perhaps, the empirically relevant cases. We examine the optimum rent-extracting tariff for what is perhaps the best-understood and most frequently employed oligopoly model: the Cournot model.

The setting involves a foreign oligopoly which considers the domestic country as a well-defined distinct market. There are $\mathrm{n}$ identical firms, and each firm has variable profit $\pi$, export level $x$, and constant marginal cost $c^{\prime}$. Then, for the specific tariff case, $\pi=x p(x)-c^{\prime} x-t x$, where $x=n x$, with associated first order condition $\pi_{x}=x p^{\prime}+p-c^{\prime}-t=0$.

Taking ( $\left.6^{\prime}\right)$, multiplying numerator and denominator by $\mathrm{P}^{\prime}$, noting that $P_{t}=P^{\prime} X_{t}$, and using the first order condition yields

$$
t *=n\left(p-c^{\prime}-t *\right) q_{t} / p_{t}
$$

This expression indicates that a non-zero $t *$ depends on the distortion $p>c^{\prime}:$ if $p=c^{\prime}, t^{*}=0$ is the solution to (20). Also the optimal specific tariff is higher the greater its incidence, $q_{t}$, to foreign producers relative to its.incidence, $P_{t}$, to domestic consumers. After solving for the comparative static effects ${ }^{10} x_{t}=n / p^{\prime}(n+1+R)$ and $p_{t}=n /(n+1+R)$ we obtain, from (6), $t *=-p^{\prime} x(1+R) / n$ 
As before, whether $t^{*}$ is positive or negative depends on $R$ : the relative curvature of demand. The critical condition for a subsidy, $R<-1$, is independent of the number of firms and therefore holds for both monopoly and Cournot oligopoly. However, the magnitude of $t^{*}$ diminishes, for any given $R$, as $n$ rises. (In general, of course, $R$ may vary along the demand curve, but the general tendency of increases in $n$ to decrease $t *$ is clear.)

In the case of an ad valorem tariff $v$, the argument of Section 4 is easily extended to the oligopoly case. A subsidy will, as before, be welfare-improving if $\mathrm{dq} / \mathrm{dv}<0$. It is easily shown that the condition corresponding to (18) is

$$
q(v)=n \eta c^{\prime} /(n \eta-1)
$$

from which it follows, once again, that whether or not a subsidy is optimal depends on whether $\eta$ rises or falls along the demand curve. Therefore, for the ad valorem case as well as for the specific tariff/subsidy case, the conditions under which a subsidy or tariff is welfareimproving are unchanged by the addition of more firms.

\section{Noncooperative Equilibrium}

The strategy variable of the exporting country is the extent of cartelization and the strategy variable of the importing country is the tariff or subsidy level. A noncooperative equilibrium arises when, given the level of the strategy variable chosen by the other country, each country is maximizing with respect to 1 ts own strategy variable. We can think of the extent of cartelization as being measured by the number of independent noncooperative decision-making units in the export industry, which we refer to as the number of "firms". 
If the objective of the foreign government is to maximize welfare as measured by conventional surplus measures, and if sales of the imperfectly competitive good in the foreign country are negligible when compared with exports, then the interests of the government coincide with those of the industry. In this case the "bestresponse" or "reaction" to any tariff or subsidy is full cartelization of the industry. The reaction function, defining the optimal number of firms, $n$, as a function of the tariff level, $t$, is a vertical line at $\mathrm{n}=\mathrm{l}$ in $\mathrm{n}, \mathrm{t}$ space (In this section we restrict attention to the specific tariff, so as to save space. Similar analysis can be carried out for the ad valorem case.)

The reaction function of the consuming country $t *(n)$, showing the optimal tariff as a function of the degree of foreign cartelization, is normally downward sloping. (This is certainly true for the specific tariff with linear demand and constant marginal cost. ${ }^{11}$ ) The reaction function is drawn sloping downward in Figure 4, and, as shown, the equilibrium (point A) consists of a monopoly cartel and the best-response specific tariff calculated in Section 3 .

\section{- Figure 4 -}

There are two points to be made about this noncooperative equilibrium. First, it is clearly inefficient. The "first-best" outcome involves price equal to marginal cost and a zero tariff. However, despite this inefficiency the noncooperative equilibrium is better for the exporting country than the first-best outcome, in which all surplus accrues to the consuming 
nation. This is a simple but important point. Trade liberalization in a particular industry is not likely to improve the welfare of all countries involved. For trade liberalization to be successful one should expect to see agreements in which each country makes concessions in some industries in return for advantages in others.

If the exporting nation also consumes the product at home, the national case for cartelization is not so clear since cartelization reduces the welfare of domestic consumers. Auquier and Caves (1979) consider this tradeoff between gains from exports to foreign markets and domestic losses due to cartelization using the price cost margin as the measure of cartelization.

Here, however, we think of the number of firms as the choice variable, and the point can be made rather easily. Assuming, for ease of illustration, constant marginal cost, the objective function of the exporting country is

$$
G^{*}=(p-t) X(t)+U^{*}\left(X^{*}\right)-c\left(X+X^{*}\right)
$$

where asterisks denote variables associated with the exporting country. Maximizing with respect to $n$ yields

$$
d G^{*} / d n \equiv G_{n}^{*}=\left(P+X P^{\prime}-c-t\right) d X / d n+\left(p^{*}-c\right)(d X * / d n)=0
$$

where we assume that the cartel may charge different prices in its home and foreign markets ( $\mathrm{p}$ and $\mathrm{p}^{*}$ may differ). Under noncooperative (Cournot) oligopoly the first order condition of each firm in its export market is $p+x p^{\prime}-c-t=0$, and adding $(n-1) x p^{\prime}$ to both sides of thisyields

$$
p+x_{p}^{\prime}-c-t=(n-1) x p '
$$


Substituting (25) into (24) and using $x_{n}$ and $x_{n}^{*}$ to denote $d x / d n$ and $\mathrm{dX} * / \mathrm{dn}$ respectively, we have

$$
n=-\left(x_{n}^{*} / x_{n}\right)\left(p^{*}-c\right) / x p '+1
$$

Expression (24) is not a reduced form, but it is sufficient to a11ow a clear understanding of the economics involved. If there is no home consumption, $X^{*}$ and $X_{n}^{*}$ are zero, so the optimal response is $n=1$. If there are no export sales $x$ and $X_{n}$ are zero and the optimum is $f$ or $n$ to become arbitrarily large, to achieve the domestic competitive outcome. In the intermediate range $n$ exceeds 1 , with $n$ being greater as responses in the home market are relatively more important.

In this case, since $x, P, P^{\prime}$ and $x_{n}^{*}$ all depend on the tariff set by the importing country, the optimum $n$ is no longer independent of the tariff. It is possible, for particular demand structures, that the reaction function in $(n, t)$ space might be downward-sloping. However, the reaction function would generally tend to be upward sloping because the export market becomes relatively less important as the tariff rises. A noncooperative equilibrium such as point B illustrated in Figure 4 would emerge. 


\section{Concluding Remarks}

National governments can be expected to perceive incentives to intervene in international markets that are potentially imperfectly competitive. Just as there is a wide variety of technological and behavioural structures in various industries, there is also a wide variety of policy intervention tools available. In this paper we have focused on two fairly straightforward tools: cartelization of domestic export industries and rent-extracting tariffs in the face of imperfectly competitive imports.

Both specific tariffs and ad valorem tariffs are considered in the paper. In both cases we find, surprisingly, that either a tariff or a subsidy may be the optimal response, depending on the nature of demand and cost. In the specific tariff regime the relevant variable is the relative curvature of demand, $X_{P}{ }^{\prime \prime} / P^{\prime}$, which we denoted by $R$. With constant marginal cost a tariff or subsidy is optimal depending on whether $\mathrm{R}$ exceeds or falls short of minus one, respectively. A specific subsidy would, for example, be implied by constant elasticity demand. In the ad valorem case it is the change in the elasticity of demand along the demand curve that is the critical indicator. If the elasticity of demand decreases as one moves down the curve (as with linear demand) a tariff is welfare-improving; if the elasticity increases a subsidy is welfare-improving.

The change in the elasticity is not unrelated to $R$ and, in particular, for an ad valorem subsidy to be optimal $R$ must certainly be less than minus one in the constant marginal cost case. Thus a subsidy is less 
likely to be welfare-improving in the ad valorem than in the specific

regime. In both regimes the subsidy case requires strongly convex

demand and would have to be considered unusual. Also, in both regimes the critical condition for a tariff or subsidy to be welfare-improving holds generally for a foreign cartel or for foreign Cournot oligopoly, irrespective of the number of firms.

In the case of the subsidy we have shown that both countries gain, but normally distortionary interventionist policies tend to be of the "beggarthy-neighbour" sort. One country's gain is another country's loss, and there is usually an additional deadweight loss in the bargain. Nevertheless, a noncooperative international trade equilibrium will involve intervention of this sort. In the simple case of a potential export cartel (without home consumption) the equilibrium involves a monopoly cartel and the corresponding optimal tariff.

This paper provides support for the multilateral approach to trade liberalization. The result of unilateral pursuit of domestic objectives would not be a desirable outcome. Trade liberalization is not a matter of countries getting together and agreeing to "do the sensible thing". On the contrary, we might expect that in return for some kind of liberalization in its own policies, each country would require compensation in form of liberalization in other country's policies. Unfortunately, efficient liberalized policies do not constitute a natural noncooperative equilibrium, and are likely to require regular reinforcement if they are to survive. 


\section{Footnotes}

* The authors would like to thank the referee for very helpful comments, particularly for his suggestions concerning the treatment of ad valorem tariffs and subsidies. They would also like to thank participants of the 1983 NBER Summer Institute for International Studies. J. Brander gratefully acknowledges financial support from a Social Sciences and Humanities Research Council of Canada post-doctoral fellowship.

1. The idea of using domestic policy to promote the potential monopoly power of domestic firms has been considered by Basevi (1969). Frenkel (1971), and Auquier and Caves (1979). Krugman (1983) has an interesting analysis of the effects of protected home markets.

2. The idea that imperfect competition might, from the point of view of one country, call for policy intervention has of course been recognized in the "distortions" literature (see, in particular, Bhagwati (1971)). Corden (1974) points out some second best policy incentives that might arise under imperfect competition.

3. The idea that rent can be extracted from a foreign monopoly is presented by Katrak (1977) and Svedburg (1979), who construct linear examples, and is an implicit theme in the state-trading-literature. (See, for example, Just, Schmitz and Silberman (1979) and Stegemann (1981).) Brander and Spencer (1981) examine the use of a tariff to extract rent from an entry-deterring foreign monopolist and Bergstrom (1982) considers the noncooperative tariff response to OPEC by consuming nations.

4. $R$ may look familiar because it has the same algebraic form as the formula for relative risk aversion (with $X$ as wealth and $p$ as utility).

5. The possibility of a subsidy is consistent with second order condition $G_{\text {t }}<0$, for the importing country. For example, with constant marginal cost and constant elasticity demand, $G_{t t}=X_{t}((1+R) \mu+1)$, which is negative if $R<-1$.

6. We are indebted to the referee for suggesting consideration of the ad valorem case, deriving expression (18), and obtaining the result relating $q_{v}$ to changes in the elasticity of demand along the demand curve. The method of derivation we have used differs from that offered by the referee, who based his analysis on marginal changes from the zero tariff point rather than on local conditions near the optimum. In both cases one needs to rely on overall concavity of $G$ in the choice variable for the arguments to be complete. 
7. The condition $\eta_{X}<0$ is necessary and sufficient for an ad valorem subsidy to be welfare improving. Since $\eta=-p / p^{\prime} X, \eta_{X}=-\left(\left(p^{\prime}\right)^{2} X-\right.$ $\left.p\left(p^{\prime}+X p^{\prime \prime}\right)\right) /\left(p^{\prime} X\right)^{2}$ from which it follows that $\eta_{X}$ has the same sign as $P^{\prime} X-P(l+R)$ where $R=X P^{\prime \prime} / P^{\prime}$. Since $P^{\prime}<0$, clearly $R<-l$ is necessary but not sufficient for $\eta_{X}>0$

8. The condition $P_{t}>1$ is of course only a marginal condition. Along the path from nonintervention to the optimal subsidy, $p_{t}$ might conceivably be smaller than one in some ranges, since $\mathrm{P}_{t}$ is endogenous and varies along the demand curve. It is fairly clear that an optimal subsidy must discretely lower price. For many common demand structures, including linear and constant elasticity demand (and provided marginal cost is constant) marginal and discrete effects have the same sign.

9. We should mention here the possibility of multiple local optima. It is possible that first order condition (6) might have several solutions, and that one solution might imply a tariff while another implied subsidization. Global concavity of $G$ in $t$ will of course rule out multiple solutions, and in the familiar examples of linear and constant elasticity demand, with constant marginal cost, the solution is unique. In any case, the overall optimum is well-defined. The interesting point is that there may be both a tariff and a subsidy that would shift out the equilibrium balanced trade line.

10. The comparative static effects $\ddot{s}_{t}$ and $p_{t}$ are calculated in the same manner as for the monopoly case. The one point to note is that $x_{t}=-\left(\partial \pi x^{/ \partial t}\right) / \alpha$ where $\alpha=p^{\prime}+n\left(p^{\prime}+x p^{\prime \prime}\right)=p^{\prime}(n+1+R)$, and $\alpha<0$ for local stability. (See Seade 1980, p. 483.) $\alpha$ takes the place of the second order condition because actual equilibrium changes in $X$ differ from the beliefs held by firms. Then, since $\partial \pi / \partial t=-1$ and $x_{t}=n x_{t}$, the comparative static effects in the
text follow.

11. With linear demand $R=0$, so from (2l) $t^{*}=-p^{\prime} x$ if marginal cost is constant. Then $d t * / d n \equiv t \underset{n}{*}=-p^{\prime}\left(x_{n}+x_{t} t \underset{n}{*}\right)$ or, collecting terms in $t * t_{n}^{*}, t_{n}^{*}=-p^{\prime} x_{n} /\left(1+p^{\prime} x_{t}\right)$, which is negative since $x_{n}<0$ in this case 


\section{$\underline{\text { References }}$}

Auquier, A. and Caves, R., (1979) "Monopolistic Export Industries, Trade, Taxes and Optimal Competition Policy" Economic Journal 89, 559-81.

Basevi, G. (1970) "Domestic Demand and the Ability to Export", Journal of Political Economy 18, 330-337.

Bergstrom, T. (1982) "Capturing Oil Rents with a National Excise Tax", American Economic Review 71,

Bhagwati, J., Ramaswami, V.K., and T.N. Srinivasan (1969), "Domestic Distortions, Tariffs and the Theory of Optimum Subsidy: Some Further Results." Journal of Political Economy, 77, 1005-1010.

Bhagwati, J. (1971) "The Generalized Theory of Distortions and Welfare", in J. Bhagwati et al. (editors) Trade, Balonce of Payments and Growtr, (Chicago and Amsterdam: Rand-McNally and North-Holland.)

Brander, J. and Spencer, B.J. (1981) "Tariffs and the Extraction of Foreign Monopoly Rents under Potential Entry", Canadian Journal of Economics $14,371-389$.

Brander, J. and Spencer, B.J. (1983) "Tariff Protection and Imperfect Competition" in H. Kierzkowski ed. Monopolistic Competition and International Trade (Oxford University Press) (Forthcoming).

Corden, W.M. (1974) Trade Policy and Economic Welfare (Oxford University Press: London).

De Meza, D. (1979) "Commerical Policy Towards Multinational Monopolies - Reservations on Katrak", Oxford Economic Papers 31, 334-7.

Frenkel, J. (1971) "On Domestic Demand and Ability to Export", Journal of Political Economy 79, 668-72.

Johnson, H. (1953), "Optimum Tariffs and Retaliation", Review of Economic Studies, 21, 142-153.

Johnson, H. (1965), "Optimal Trade Intervention in the Presence of Domestic Distortions", in R.E. Baldwin et al. (Eds.), Trade, Growth and the Balance of Payments, (Chicago: Rand-McNally).

Just, R.E., Schmitz, A. and Zilberman, D. (1979) "Price Controls and Optimal Export Policies Under Alternative Market Structures", American Economic Review 69, 706-14.

Katrak, H. (1977) "Multinational Monopolies and Commercial Policy", Oxford Economic Papers 29, 283-91. 
Krugman, P. (1983) "Import Pretection as Export Promotion" in H. Kierzkowski ed. Monopolistic Competition and International Trade (Oxford University Press) (forthcoming).

Seade, J. (1980) "On the Effects of Entry", Econometrica 48, 479-489.

Stegemann, K. (1981) "State Trading and Domestic Distortions in a Mixed World Economy", in M.M. Kostecki, ed. State Trading in International Markets (London: MacMillan).

Svedberg, P. (1979) "Optimal Tariff Policy on Imports from Multinationals", Economic Record 55 (March), 64-67. 
Figure 1

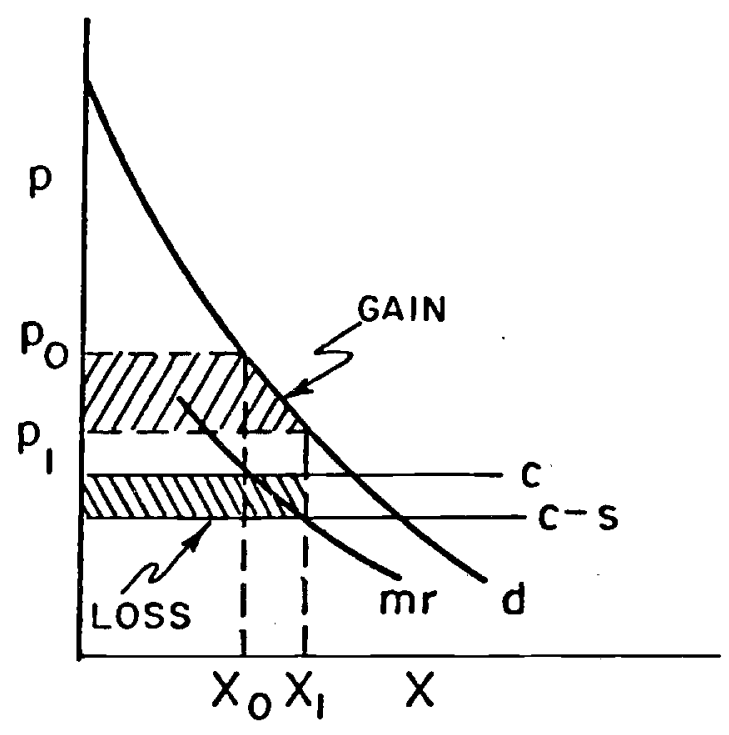


Figure 2

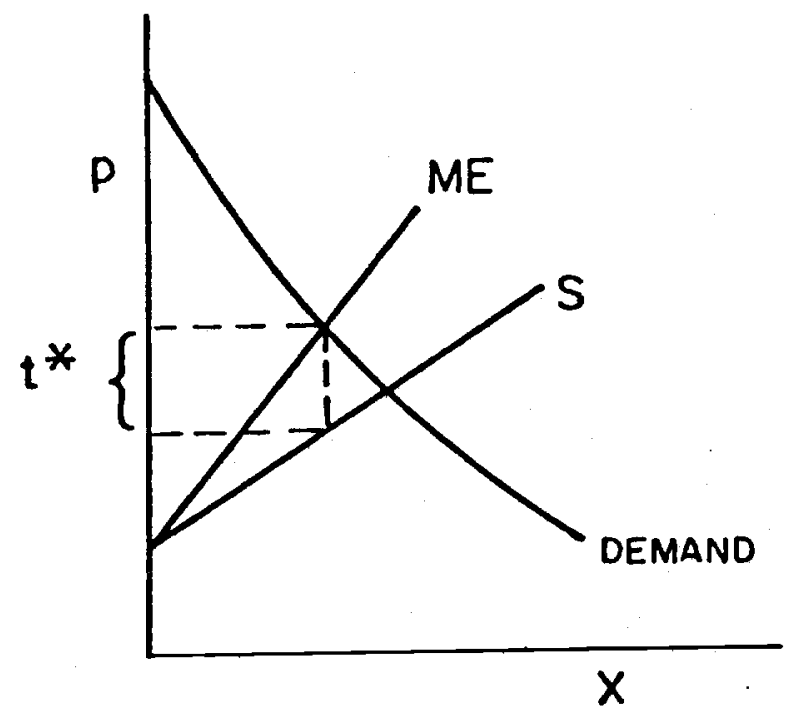


Figure 4

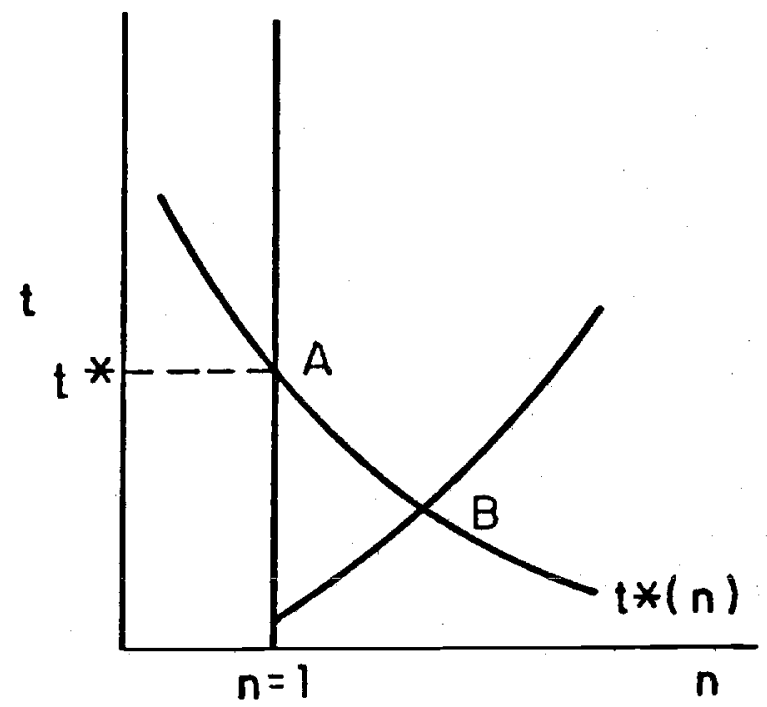


Figure 3

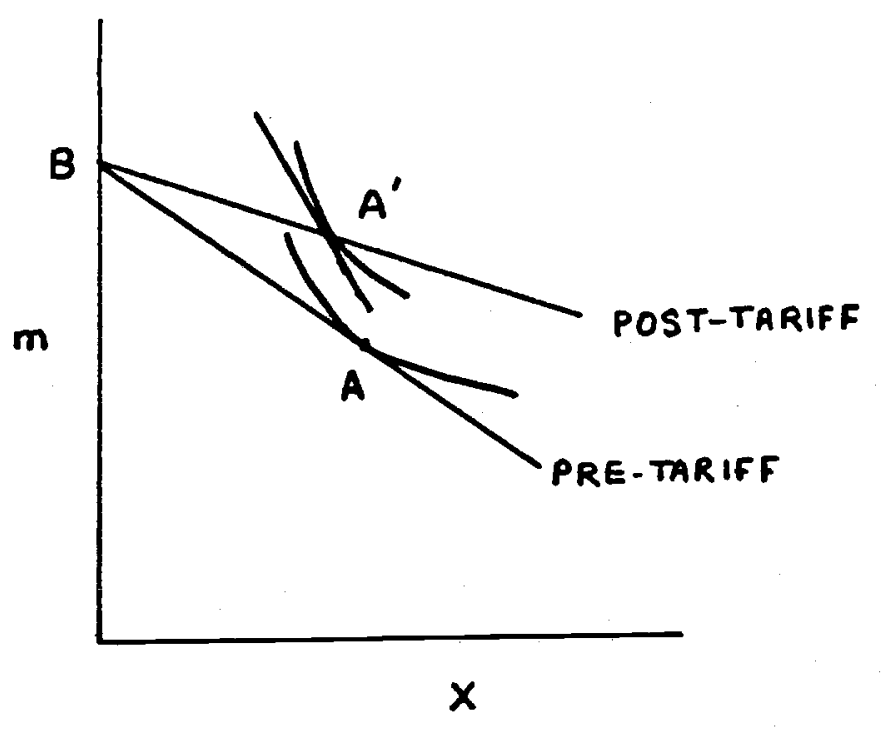

